\title{
ADOPTION AND IMPLEMENTATION OF CLOUD COMPUTING SERVICES: A RAILROAD COMPANY CASE
}

\author{
Dalsang Chung, Governors State University, dchung@govst.edu \\ Sun Gi Chun, Alabama State University, sungichun@alasu.edu
}

\begin{abstract}
Under the competitive global business environment, businesses concentrate on technological advancements which are critical for boosting their levels of productivity, increasing profits, and gaining market share. As one of technological advancements, cloud computing has gained momentum during the last few years by service providers who offer technological resources that were only available by dedicated servers in the past. This paper focuses on a railroad company case of the cloud based solution in terms of IT infrastructure, adoption, and implementation process based on the contract made by a cloud computing service provider, 411 Solutions International and a railroad company. Moreover, the study is to analyze the impact of the cloud based solution in terms of benefits and other efficiency. Based on the company case, the involvement of current employees as well as management is pivotal during the review, selection, and rollout phases of the implementation. Also, cloud computing was the key for creating important competitive advantages, saving costs, and increasing employees' performance and productivity. Also, customer satisfaction has been enlarged considerably because the company can quickly respond to emerging markets after the adoption and implementation of cloud computing.
\end{abstract}

Keywords: Cloud Computing Services, Railroad

\section{INTRODUCTION}

According to the Gartner Group, spending on shared cloud services will grow 18\% in 2013 to $\$ 132$ billion and almost $\$ 250$ billion by 2017 [7]. In the media, cloud computing becomes from a hot topic to mainstream news. Many trade journals and newspapers have been published about all the hypes of cloud computing and benefits associated with it. By examining a company case of the cloud computing service, we can discover that all hypes and the benefits associated with the adoption and implementation of the cloud computing services are real. Also we can find out how helpful the cloud computing service would be to users. However, it was not easy to contact staffs in IT department of a company that adopted and implemented cloud-computing services because staffs in IT department were very busy within the organization, and they could not spare time for an interview. After numerous trials to contact through calls and e-mails, an interview was finally made with an IT staff from a railroad company that adopted and implemented cloud-computing services.

The main problem with the railroad company was their aging IT systems and infrastructure that constrained efficiency of resources and reliability of the company; therefore, they did not quickly respond to changing needs of customers and make the sharing of data difficult. They were also unable to cope with the scale of growth experienced during the last few years. To solve the problems, the company considered cloud computing as an option and contacted several cloud computing service providers to do preliminary and feasibility study. After evaluating their proposals, the company chose a clouding computing service provider, that is, 411Solution International that helped implement cloud computing. Based on the company case, the involvement of current employees as well as management was crucial during the review, selection, and rollout phases of the implementation. Also, cloud computing was the key for creating important competitive advantages, saving costs, and increasing employees' performance and productivity. Also, customer satisfaction has been enlarged considerably because the company can quickly respond to emerging markets after the adoption and implementation of cloud computing.

The objective of the paper will explain about diverse cloud computing services offered to a company. Then, risks and concerns for adopting and implementing cloud computing services in a company will be addressed. Then, 
background and history about the railroad industry will be mentioned. Then the railroad company case explains main problems and technological needs for adopting and implementing the cloud computing services by comparing the old and new IT infrastructures. As a solution, a cloud provider, 411 Solutions International as IBM business partner will be introduced which provides VMware cloud computing services to the railroad company. Finally, conclusion will be drawn on benefits from cloud computing services and knowledge learned from the adoption and implementation process for cloud computing.

\section{LITERATURE REVIEW}

Based on the literature search using library database, Google, and Yahoo, few research have found on the adoption and implementing cloud computing services in the railroad industry. This section covers definition, issues, and concerns on cloud computing services.

Cloud computing is a broad term that describes the shift from conventional hosted services in privately owned servers to data and services be ing accessed through the Internet. The cloud is the network where applications, data, and services are accessed online. Cloud computing services differ from cloud computing in that they are essentially any service that can be delivered and consumed over the Internet in real-time [6]. Cloud computing is the entire framework that enables these services to exist and be consumed. Cloud computing services are offered at three different levels as follows [9]:

1) Software as a Service (SaaS): cloud based delivery of complete software applications that run on the infrastructure the SaaS provider manages. SaaS applications are accessed over the Internet and typically charged on a subscription basis.

2) Platform as a Service (PaaS): delivery of a virtualized application runtime platform that has a software stack for developing applications or application services. PaaS applications and infrastructure are run and managed by the service provider.

3) Infrastructure as a Service (IaaS): Delivery of raw, virtualized computing infrastructure such as servers and storage as a service to build applications. IaaS providers help customize infrastructure to customers' application needs.

The service level of application is most likely decided by consumers. Popular applications are web-based e-mail, calendars, photo and video storage, social networking sites, office productivity software, and even more complex tools such as Photoshop. At one click, users can get access up to super computer capacity with the low cost and mobility.

Based on the cloud deployment method, there are two types of cloud computing, that is, public and private clouds. For public clouds, computing resources are dynamically deployed to users by third party providers. Third party providers share computing resources with users and charge them based on the usage. The providers offer scalability and flexibility with the pay-as-you-go model that is feasible especially for small businesses [10]. Amazon's Web Services and Google's AppEngine are good examples of public clouds. For private clouds, computing resources including infrastructure are exclusively deployed to a particular company. The clouds are more secure because they belong exclusively to a particular company. Hybrid clouds integrate positive aspects of both public and private clouds. For example, for hybrid clouds, critical services with rigorous security requirements can be presented on private clouds while less critical services can be offered on the public clouds.

Cloud computing is used to maximize growing opportunity for challenging firms by providing innovation in the cost reduction, new customer relationship, and competitive edge [13]. As new customer relationship, the authors took an example of Salesforce.com where 170,000 customer applications have been built on Heroku, the Salesforce.com cloud platform for developing close customer relationship. In the automobile industry, Toyota adopted cloud computing to provide competitive edges by meeting technological challenges such as increasing technology components in the car including GPS systems, rising collaboration with automobile original equipment manufacturers (OEM) in other countries such as China and India, growing amount of data to analyze, cost reduction, and data security [16].

Cloud computing is not always accepted because of expected savings, explains John Blossom, President of Shore Communications [5]. The Shore Communications is a consulting firm advising content and technology 
companies on marketing strategies. "Recent research is implying that there can be 10 to 20 times return on investment for many cloud computing services," says Blossom. "At the same time security risks of using common web-based infrastructure are being reduced through more efficient implementation of security standards." The security concerns include unauthorized access without knowing where the data is stored, and loss and recovery of confidential data. A cloud security model was developed to prevent from malicious attacks in the health, banking, and telecommunication industries [14]. Cloud computing can be vulnerable because cloud computing employs the comprehensive use of network and Web technologies. Other risks on cloud computing are regulatory compliance, data location, investigative support, provider lock-in, and disaster recovery [4]. The authors recommended that the adoption of cloud computing depended on the company size and technological advancement of the company. In other words, the larger the size of the company and the more technologically advanced company are ready to adopt cloud computing.

\section{Cloud Computing Concern}

While cloud computing can save time, money and effort, the nature of cloud computing applications as well as their dependence on broadband Internet pose some serious issues for its users [2]. Firstly, cloud computing would not result in saving time, money, and effort if companies initially implementing the cloud does not have qualified IT staff, infrastructure, and the required speed of the Internet connection to use the cloud. For example, even if companies can connect to the Internet with the minimum download speed of $3 \mathrm{Mega}$ bits per second (Mbps), upload speed which is usually slower than download speed should be matched with additional costs because all information are to be stored online [5].

Secondly, the most significant issue is privacy while much of the appeal of cloud computing lies in its high level of scalability. Information stored in the cloud is looked after by the service provider, which means that consumers share control over their information with the provider $[12,14]$. This creates a range of privacy and security issues as well as legal concerns as to who owns and has access to the information.

Thirdly, there is a question of how users' information may be used by service providers or third parties. Because cloud-computing services offer unlimited storage space, it becomes unnecessary to delete information or content that the consumer has added. This in turn creates enormous amounts of lucrative data that can be sold depending on the ownership of the information, which poses another issue to consumers. Even when information such as an email is deleted, it often still exists somewhere retaining the content. In 2009, Facebook changed its Terms of Service, suggesting that all original content is owned by Facebook, even if the user deletes their account. When you include information that involves medical and financial records, calendars as well as other potentially sensitive information, questions of who owns that data regardless of current or deleted, and who is entitled to use it, become important. Therefore, some authors recommend not to store personally sensitive information such as date of birth, social security number, medical records, and financial records at Google drive [3].

Fourthly, there are issues of accountability for how the data is managed. If the cloud fails, can users get access to their information from somewhere else? Or if they decide to move clouds, for example, migrating from Google to Yahoo, can their data be transferred? By relying on cloud computing, users are entrusting all of their information to a service provider. If the cloud fails, who is responsible for recovering that lost information, and for any costs or damages incurred by that loss? Storing information somewhere out of the user's control requires confidence that the provider will be accountable for the protection of that data. A model to secure users' control and accountability over data on the cloud was developed using authentication procedures at the logging on the cloud [15].

Fifthly, the issue of mobility between clouds raises the more fundamental issue of connectivity between them. Clouds function in ways that recall in some respects the closed, proprietary networks of the 1980s and 90 s such as CompuServe or AOL. The tremendous benefit of the Internet as it emerged in the 1990s was the capacity for users to communicate across networks, but we may now be losing some of that freedom. Some experts have suggested that the next major challenge for Internet architects will be ensuring clouds to communicate with each other [11]. 


\section{THE RAILROAD INDUSTRY}

The story of railroads is the story of a growing America. Early development in America was limited largely to the coast and areas adjacent to waterways. Development of the railroad changed that by unlocking large amounts of natural resources and allowing population centers to develop in areas previously considered unreachable. As the nation grew, so did the railroads stretching across the country's plains and mountains and up and down its coasts. Most of the nation's major cities and industrial centers can attribute their growth to commerce generated by the railroad.

The first rail was laid in the United States in 1828. By 1848, the rail network had grown to nearly 6,000 miles. By 1852, six rail lines had breached the Appalachian Mountains and the first had reached Chicago. By 1860, Chicago boasted service to more than 11 railroads. The railroad industry influenced farmers on selecting their agricultural area. For example, dairying was developed along railroad lines. In 1851, cooled milk was moved from northern New York State to Boston. Grain could be shipped from Illinois, Wisconsin, and Michigan to Liverpool and London. Manufactured products could be cheaply transported west, and living standards of farmers improved. Farmers responded to the availability of cheap capital goods with increased commercial farming, and made more profits with the building of railroads. However, new commercial ways made the farmers dependent on railroads. Major cities and the South experienced similar changes. Fruit and vegetable growing and dairying were developed to supply Chicago, St. Louis, Cincinnati, and other cities. The rise of Wisconsin as a famous dairying area can be connected to the growth of Chicago. Chicago merchants and railroads also reached into the Deep South for various horticultural specialties. Since 1900, the Chicago railway has been an integral part of the railroad operations. A series of connecting railroad were constructed to link every major railroad in Illinois. The railway grew by adding facilities, elevating part of its tracks, and performing better. In 1910, the railroad began enlarging its facilities and adding additional railroads in Minnesota, Chicago, Illinois, Pennsylvania, Indiana, and Ohio. Due to mergers over the years and bankruptcy of the Chicago railway, some of Chicago rails are owned by six major railroad companies. The six major railroad companies are: Burlington Northern Santa Fe Corporation, Canadian National, Canadian Pacific Railway, CSX Transportation, Norfolk Southern Corporation, and Union Pacific Railroad.

\section{COMPANY AND PROBLEMS}

The railroad company for the study operates a large switching terminal railroad in the United States. The company has several miles of the mainline route with more than 300 miles of switching tracks, allowing it to interchange with every railroad serving the Chicago rail hub. Chicago is one of the largest hubs of the railroad industry and only a small number of rail cars travel transcontinental without coming through Chicago. The company dispatches more than 9,000 rail cars per day. The employees can identify 50 miles of trains with the aid of IT network and infrastructure. The company serves approximately 100 industries such as fresh produce, grain, steel, metal, glass, paper, oil, snack foods, candy, and many other distributors. The industrial traffic consists of a majority of primary metals, chemicals and petroleum products, food products, scrap iron, coal \& coke, whole grain, and a variety of other products including lumber, paper, and aggregates.

It is known that rail freight companies in general are experiencing growth in trade, especially in the areas of energy and commodities. Railroad companies are increasing asset utilization and making significant investments in infrastructure to meet the challenging capacity. The main problem with the railroad company was their aging IT systems, already carrying for a few years. Aging systems constrained efficiency of resources and reliability of the company; moreover, they did not allow responding quickly to changing needs of customers. Old IT infrastructure had too many servers, switches, and networking equipment. Seven (7) dynamic host configuration protocol (DHCP) servers were: Transportation server, Mechanical server, Management Information System server, Engineering server, Accounting server, Administration server, and Visitor server. There needed to be an easier way for each department to communicate with each other and a strategy to cut back on DHCP servers. Three (3) virtual local area network (VLAN) switches were: switch 1 (Accounting, Mechanical, and Engineering), switch 2 (MIS, Administration, and Visitors), and switch 3 (Transportation, and Business Communication). Also they had six (6) wireless routers and three (3) wired routers to provide Internet services to employees. The company needed to cut back on VLAN switches and other networking equipment because there were too many VLAN switches and other networking equipment. 
Network failures and systems outages were common and produced very negative effects on the company which in turn negatively impacted customer satisfaction. The previous IT systems was old and complex, which made the sharing of data difficult. They were also unable to cope with the scale of growth experienced during the last few years.

An open-ended interview was made with IT staff of the railroad company for a couple of hours on a weekday of April 2014 about the adoption and implementation of cloud computing. Table 1 shows detailed interview questions and answers. Other information on the company, IT systems and infrastructure, main problems and solution, and issues in the adoption and implementation process were collected at that time.

Based on the interview with IT staff (Refer to Q1 in the Table 1), cloud computing reduced capital expenditures because they did not have to purchase networking devices, servers, switches, and routers. Cloud computing also lessoned maintenance costs for the purchased equipment. Moreover, reliability of the cloud computing helped serve customers better. Even if cloud computing needed technology infrastructure to guarantee fast and reliable Internet connection, cloud computing provided competitive edge by reducing costs and improving efficiency that was achieved by flexibly utilizing adequate resources (Refer to Q5 in the Table 1). Companies in the railroad industry have already utilized cloud-computing services to improve efficiency and solve obsolete IT infrastructure and systems (Refer to Q6 in the Table 1). Main worries for implementing cloud computing was reliable Internet connectivity because without Internet connection, the whole operation would be down, which was very risky (Refer to Q7 in the Table 1). Also, costs and security were major factors for deciding the adoption of cloud computing.

\section{CLOUD COMPUTING SOLUTION}

Today's increasing demand for freight railroad services continues to outpace available capacity and infrastructure, while aging systems and traditional business practices limit tangible responses to address the problem. The railroad company for the study is not an exception. The company jumped into the $21^{\text {st }}$ century bandwagon by embracing new and innovative technologies to acquire, associate, and analyze information across the rail network and using that information to become more efficient and effective under the responsive and agile operating environment.

For fulfilling technological needs, top management reviewed three (3) options: purchase, lease, and rent. While renting technical services was suitable for meeting short term needs, leasing and buying options suitable for meeting long term needs depended on cash flow and other financial conditions of the company (Refer to Q4 in the Table 1).

The railroad company evaluated proposals of four (4) cloud service providers out of which 411 Solution International was selected for implementing cloud computing services because 411 Solution proposed the services with the lowest price (Refer to Q8 in the Table 1).

\section{Solution International}

411 Solutions is a metro Chicago technology partner of IBM focusing on the removal of complex management of IT infrastructures that support businesses. The service provider is nationally ranked in the top 5\% for all IBM partners [1]. For nearly twenty years, 411 Solutions has aided companies by improving uptime, reliability, and performance of the IT infrastructures. The vendor offers business continuity recovery solutions that help businesses continue to operate during unplanned downtime, power outages, hardware failure, and disasters. The offsite data backup and recovery services allow businesses to take their IT needs offsite and let the service provider handle them. The vendor also offers a variety of hosted and managed services that eliminate the day-to-day hands-on attention required before.

Other services provided by the vendor are 1) technical and strategic consultation about state-of-the-art technology, 2) offsite data backup and recovery service, 3) access to the latest technology and the newest applications without management and maintenance hassle, 4) secure place to house production or backup systems and an alternate work area in case of facility compromises, 5) immediate access to highly trained and certified experts for any IT project, 6) highly available systems services, 7) colocation server hosting, 8) cloud server hosting, 9) online server backups, 10) managed services, and 11) disaster recovery data services. 
Table 1. Questions and Answers made through an interview with IT staff

\begin{tabular}{|c|c|}
\hline Q1 & What is your opinion about cloud computing? \\
\hline Answer & $\begin{array}{l}\text { Cloud computing dramatically decreases day-to-day maintenance operations for hardware equipment as } \\
\text { well as increase reliability of infrastructure because of the redundancy built into the nature of cloud } \\
\text { computing. Also the cost of cloud computing compared to that of owning equipment can intensely } \\
\text { decrease because there is no upfront cost of owning the equipment and maintenance contracts on the } \\
\text { equipment. However, for most organizations and their applications, cloud computing still has some } \\
\text { security concerns. Moreover, added requirements for the Internet bandwidth need to be considered. } \\
\text { This will probably be settled in the future as Internet service providers (ISP) become more competitive } \\
\text { and affordable. }\end{array}$ \\
\hline Q2 & How much do you spend annually on IT infrastructure and IT operations? \\
\hline Answer & $\begin{array}{l}\text { Approximately } \$ 250,000.00 \text { has been spent annually. Most of the budget goes to licensing fees, } \\
\text { vendor fees, and office peripherals. }\end{array}$ \\
\hline Q3 & How did you and your company decide to adopt cloud computing? \\
\hline Answer & $\begin{array}{l}\text { As an IT manager, I am always looking for ways to decrease the cost. Even though costs incur in } \\
\text { association with IT infrastructure, cloud computing can save long-term costs if it is correctly } \\
\text { implemented. }\end{array}$ \\
\hline Q4 & $\begin{array}{l}\text { As the representative of your company, do you prefer to buy a new car, leasing a car, or hiring a cab } \\
\text { whenever you need it? }\end{array}$ \\
\hline Answer & $\begin{array}{l}\text { Having the latest and greatest is a double edge sword. Being the first company to implement and adopt } \\
\text { cloud computing can be risky in itself. E v e } \mathrm{n} \mathrm{th} \mathrm{o} \mathrm{u} \mathrm{g} \mathrm{h} \mathrm{there} \mathrm{are} \mathrm{plenty} \mathrm{of} \mathrm{difficulties} \mathrm{associated} \\
\text { with implementing a proven technology, it is more difficult to firstly implement a cutting edge } \\
\text { technology if not planned out properly. W h i l e } \mathrm{r} \text { enting only makes sense if the need is very short } \\
\text { term, leasing or buying depends on the cash flow and other financial conditions of the company. That } \\
\text { is a decision for the upper management. }\end{array}$ \\
\hline Q5 & Do you think cloud computing has led you to gain competitive advantage within your industry? \\
\hline Answer & $\begin{array}{l}\text { Indeed. In fact, cloud computing has vividly improved our operations by becoming more efficient and } \\
\text { competitive. The adoption and implementation of cloud solution has proven to be extremely helpful to } \\
\text { our IT staff by decreasing the workload and allowing us to focus on strategic projects of our company. } \\
\text { Also, in any organization you need to consider the driving forces. The driving force for cloud computing } \\
\text { is cost. The flexibility enters the equation if the resource requirements are going to be changing } \\
\text { significantly. When comparing costs, you need to consider saving costs from not buying too much } \\
\text { resources or being caught with too little resources. }\end{array}$ \\
\hline Q6 & Are your main competitors using a private cloud for running their IT infrastructure? \\
\hline Answer & ir applications. \\
\hline Q7 & ing the cloud in your company? \\
\hline Answer & $\begin{array}{l}\text { Our biggest concern before moving to the cloud based solution is Internet connectivity and reliability. If } \\
\text { our company loses Internet connection, we will be unable to maintain a working operation. Also, cost } \\
\text { and security played major factors during the decision making process. }\end{array}$ \\
\hline Q8 & $\begin{array}{l}\text { What is your opinion of } 411 \text { Solutions? Do you think the company is reliable for fulfilling business } \\
\text { needs? }\end{array}$ \\
\hline Answer & $\begin{array}{l}\text { Very good. Price offered by the vendor is very good compared to those made by four (4) others. We } \\
\text { compared them during the selection process. The vendor is dedicated, good to work with, and will do } \\
\text { the right thing for their customers. }\end{array}$ \\
\hline Q9 & $\begin{array}{l}\text { What was one of the major obstacles when implementing the cloud computing solution provided by } \\
411 \text { ? }\end{array}$ \\
\hline Answer & $\begin{array}{l}\text { Some of the IT personnel were resistant and afraid of the change. They thought that their jobs were } \\
\text { going to be outsourced on its entirety. Even though their duties were going to change, the } \\
\text { implementation of the cloud did not take anyone's job. It only allowed us to become more effective on } \\
\text { serving our customers and focus on other projects. }\end{array}$ \\
\hline Q10 & When your company decided to implement the cloud, why was VMware your first choice? \\
\hline Answer & $\begin{array}{l}\text { VMware has been proven and maintained strong roots in the industry. Since our operation is critical } \\
\text { and we must maintain full functionality, it would be a critical mistake not to select the best on our part in } \\
\text { the IT department. }\end{array}$ \\
\hline
\end{tabular}


In addition to ensuring operations regardless of planned or unplanned events, 411 Solutions can keep business running at optimal levels with a variety of technology services including server consolidation, migrations, and data center virtualization. Experts of the vendor have helped a variety of companies improve uptime, reliability, and performance of their IT infrastructures.

\section{Project Goal}

Project goals of the railroad company prior to the implementation of the cloud computing solution were: 1) better identifying and optimizing the profitability or cost to serve a customer and planning asset utilization and pricing in real time, 2) reducing capital expenditure and improve utilization, 3) reducing mainline train stoppages through the use of systems that were smart enough to identify real mechanical problems and failures, 4) adjusting schedules and capacity to cope with irregular operations such as holiday festivals and weather outages, and 5) increasing network velocity, capacity, and revenue through reduced congestion and increased utilization without adding locomotives.

The railroad company required a comprehensive solution that was easy to use, efficient, and reliable. It required information to be shared among stakeholders including rail companies, shippers, car owners, travel agents, municipalities, intermodal carriers, and customers. As demand increased, customer interactions with the company had to be improved. For customers, it mattered less which company transports from point A to point B. They were more concerned about how quickly, cost effectively, or easily it moved the freight. Therefore, their decision to select transit options was based on cost, efficiency, and impact to the environment. VMware is a cloud computing service that reduces IT complexity, lowers costs, and quickly serves delivery. Also, VMware helps lower total costs of ownership by minimizing unnecessary IT infrastructure investments and maintenance fees. "More than 190,000 customers and 25,000 partners depend on VMware solutions to reach the business goals [8]." The company decided to implement VMware in order to gain flexibility by developing and deploying applications running on the cloud. VMware builds a solid foundation on platforms to empower the company's cloud infrastructure. VMware provides flexibility and security while protecting the company's existing investment.

\section{Adoption and implementation Process}

Different departments in the railroad company manage day-to-day operations such as executive, mechanical, engineering, administrative, management information system, transportation, business communication, and accounting. Each department plays a crucial role in completing daily tasks of operation. The daily tasks include keeping track of trains, establishing routes for the trains to travel, recording what commodity the train is carrying, servicing the trains that arrive, fixing and maintaining the rails, sending accounting figures to the board of directors, and many other tasks involving trains.

Computer programs help assist the railroad employees complete the daily tasks of the railroad. They are Microsoft Excel, Access, Word, Nice Vision (that is, a camera system that shows all in the train yard), accounting software package, car operation program (that is, a program that keeps track of trains by the RFID tags), mapping routes software (that is, a program that shows available tracks not for trains to collide with each other), Active Directory, and Beltpack control system (that is, a program to remotely control locomotives).

There are many different buildings on the railroad property and many locations are miles away from each other on the train yard. Some of the day to day tasks involve railroad employees communicating with each other in the different buildings. The company has a computer networking infrastructure so that each department can communicate with each other. The railroad networking infrastructure has DHCP servers, firewalls, LAN switches, WAN switches, gateway, VLAN switches, wired routers, wireless routers, and access gateway. The old IT infrastructure of the railroad before implementing the cloud consisted of seven (7) DHCP servers, three (3) firewalls, a backup gateway, a LAN switch, three (3) WAN switches, three (3) VLAN switches, a access gateway, six (6) wireless routers, three (3) wired routers, IBM system storage, and IBM Blade Center.

The company's new IT infrastructure adopts the VMware cloud service as a proven technology in the industry (Refer to Q10 in the Table 1). The company leverages existing resources to avoid unnecessary infrastructure 
investments. The company can cut costs on networking equipment and eliminate some switches and servers. The company has simplified IT infrastructure while maintaining IT control. The company has pooled computer programs such as Nice Vision, car operation program, accounting software, mapping routes software, and Beltpack control system on a virtual data center. Pooled programs on the cloud help the IT staff fast download the software for users. Before, IT staff had to go to the user's computer location and run the installation program from the disk or $\mathrm{CD}$. It was very time consuming because the buildings were not connected and it required several minutes for IT staff to travel to the train yard or other buildings. The new way is that IT staff gives users temporary administrative rights to download the software by connecting to the cloud and clicking the program image. Therefore, IT staff saves time because they do not have to travel and carry out the task themselves. Now, IT staff can focus more on strategic project rather than maintenance or routine operations (Refer to Q5 in the Table 1).

Moreover, by implementing the cloud as an infrastructure as a service, 411 Solutions is responsible for all hardware. The company no longer needs to have any networking hardware on-site except for firewalls and routers and no longer needs to spend money on maintaining the hardware. 411 Solutions is responsible for maintaining hardware including servers. The company chose to purchase three (3) VMware servers with seven (7) instances on them. Additional benefits from the new IT infrastructure are gaining space in the building due to the elimination of the most networking hardware, saving money, and saving utilities due to the less consumption of electric power for cooling.

On the other hand, while the adoption and implementation process for cloud computing was properly planned and conducted, one of the major obstacles when implementing the cloud solution provided by 411 was that some IT personnel were resistant and afraid of change because they thought their jobs were going to be totally outsourced (Refer to Q9 in the Table 1). However, even though their duties were changed, the implementation of the cloud computing did not take anyone's job. Rather, it became more effective on serving customers and focus on other projects.

\section{CONCLUSIONS}

Railroad companies in U.S. must meet society's demand for rail systems that are integrated into our economy, competitive with other transportation systems, and flexible to meet global trade demands. Few studies on the adoption and implementation of cloud computing services for a specific company in the railroad industry have been found. The study contributes that the adoption and implementation of cloud computing services for a railroad company have been examined in terms of benefits and risks. As hypes on cloud computing have been published in the newspapers and trade journals, the railroad company case has affirmed that cloud computing is the key for creating important competitive advantages, saving costs, and increasing employees' performance and productivity. Customer satisfaction has been enlarged considerably because the company can quickly respond to emerging markets after the adoption and implementation of cloud computing. The technological solution for cloud computing needs to be implemented correctly in order to ensure successful results. Also, the involvement of current employees as well as management is crucial during the review, selection, and rollout phases of the implementation. Throughout the U.S. history, railroad industry is an old industry shaping the nation. Technological advances including cloud computing services need to be considered, adopted, and implemented in order to revitalize the industry and their workforce.

The limitation of the study is that only one interview with IT staff for a railroad company was made because of the rare availability of IT staff for an interview. More interviews with IT staffs from different companies in the railroad industry as well as other industries will help generalize findings about benefits and risks in association with the adoption and implementation of cloud computing services.

Suggested Questions:

What are benefits and risks of the adoption and implementation of cloud computing services for the railroad company?

What is critically important to do successful adoption and implementation of cloud computing services for the railroad company?

What is the future road map for cloud computing services for the railroad company? What are driving forces? 


\section{REFERENCES}

1. http://www.411SOLUTIONSintl.com

2. Aljabre, A. (2012). Cloud Computing for Increased Business Value. International Journal of Business and Social Science, 3(1), 234-239.

3. Brandon, J. (2012). Google Drive Begs the Question: Who Owns Your Data in the Cloud? CIO. Retrieved on the $12^{\text {th }}$ of July, 2014, available from http://www.cio.com/article/2396503/cloud-computing/googledrive-begs-the-question--who-owns-your-data-in-the-cloud-.html

4. $\quad$ Brender, N. \& Markov, L. (2013). Risk perception and risk management in cloud computing: Results from a case study of Swiss companies. International Journal of Information Management. 33(5), 726-733.

5. Espinoza, J. (2014). The Problems Heading Into the Cloud. Wall Street Journal. retrieved on the $1^{\text {st }}$ of March, 2014, available from http://online.wsj.com/news/articles/SB10001424052702303560204579248351819283242

6. Frank, G. (2008). Defining Cloud Services and Cloud Computing. IDCExchange, retrieved on the $1^{\text {st }}$ of March, 2014, available from http://blogs.idc.com/ie/?p=190.

7. Gartner Group. (2013) Forecast: Public Cloud Services, Worldwide, 2011-2017. https://www.gartner.com/doc/2642020/forecast-public-cloud-services-worldwide

8. Genova, J. (2009). The Cloud - Game Changer? Digitalmediabuzz.com, retrieved on the $1^{\text {st }}$ of March, 2014, available from Http://www.digitalmediabuzz.com/2009/05/cloudcomputingmainstream/

9. Han, Y. (2011). Cloud Computing: Case Studies and Total Costs of Ownership. Information Technology and Libraries. 30(4), 198-206.

10. Madad, A., Gharagozlou, A., \& Nejad, A. (2013). The Necessity of Using Cloud Computing in Monitoring Metropolitan Performance - Case Study: Tehran Metropolitan Urban Observatory. Journal of Geographic Information System. 5, 521-530

11. Ogozaly, R. (2014). Business Continuity and Workload Mobility for Private Cloud. CISCO blog on Data Center and Cloud. Retrieved on the $12^{\text {th }}$ of July, 2014, available from http://blogs.cisco.com/datacenter/business-continuity-and-workload-mobility-for-private-cloud-cvd-part2/

12. Privacy Rights Clearinghouse. (2010). The privacy implications of cloud computing. Retrieved on the $1^{\text {st }}$ of March, 2014, available from http://www.privacyrights.org/ar/cloud-computing.htm

13. Radar, D. (2012). How Cloud Computing Maximize the Growth Opportunities for a Firm Challenging Established Rivals. Strategy \& Leadership. 40(3), 36-43.

14. Shi, M. (2013). Capturing Strategic Competences: Cloud Security as a Case Study. Journal of Business Strategy. 34(3), 41-48.

15. Sundareswaran, S. (2012). Ensuring Distributed Accountability for Data Sharing in the Cloud. IEEE Transactions on Dependable and Secure Computing. 9(4), 556 - 568.

16. Upadhyay, P. \& De D. (2011). Toyota to Hover Over the Cloud. GMJ. 5(1\&2), 45-52.

17. VMware and Cloud Computing: An Evolutionary Approach to an IT Revolution- article from vmware.com

18. Yin, R. (2013). Case Study Research: Design and Methods. $5^{\text {th }}$ ed. SAGE Publications, Inc. 